\title{
Reestruturação produtiva e saúde do trabalhador: um estudo de caso
}

\author{
Restructuring of production and workers' \\ health: a case study
}

Maria Silvia Monteiro 1 Jorge da Rocha Gomes 2

\footnotetext{
1 Departamento de Enfermagem, Universi dade Federal de São Carlos. C.P. 676, São Carlos, SP 13565-905, Brasil.

2 Departamento de Saúde Ambiental, Faculdade de Saúde Pública, Universidade de São Paulo. Av. Dr. Arnaldo 720, São Paulo, SP 04023-062, Brasil.
}

\begin{abstract}
A bstract We performed a case study on a company focusing on the form of management and the shop floor workers, in order to identify the possible effects of partici pant work strategies on workers' health. Data on the company included its history, type of management, and organization of both production and the work process. Data on shop floor workers included age, schooling, perceptions of work, family life, recreation, and self-reported di sease history. We concluded that the characteristics of the management model adopted by the company ori ginated from ideas imported from Japan, including flexibilization of production, outsourcing, performance of multipletasks, and participation in the work process. Workers referred to participation in the work process in an ambiguous tone. Some reported posi tive effects, like greater freedom and respect, with posi tive effects on life both insi de and outsi de the workplace. For part of the group studied, the characteristics of the work organization model practiced in the company had negative effects on health, leading them to complain of insomnia, nervousness, work-related dreams, and headaches.
\end{abstract}

Key words Occupational Health; Organizational Behavior; Social Psychology

Resumo Foi realizado um estudo de caso em uma empresa tendo como objetos da pesquisa a forma deadmi nistração praticada e os trabal hadores da área de produção, e como objetivo identi fi car os possíveis efeitos das estratégi as partici pati vas no trabal ho sobre a saú de dos trabal hadores. Anali saram-se dados rel ativos à empresa: histórico, características da administração praticada, organização da produção e do processo de trabal ho; e também dados relacionados aos trabalhadores da área de produção: idade, grau de escolaridade, percepção sobre o trabalho, vida familiar, vida social, lazer e morbidade referida. Concluiu-se que as características da administração praticada tiveram origem nas idéias vindas do Japão, incluindo a flexibilização da produção, a terceirização, a polivalência e a participação no trabalho. Para os trabalhadores, a parti ci pação no trabal ho foi sempre referida de forma ambígua, al guns relatando efeitos positi vos, como maior liberdade e respeito, com boas repercussões na vida dentro efora do trabalho. Para uma parte da população estudada, as características da organização do trabal ho prati cada na empresa têm efei tos del etéri os sobre sua saúde, gerando quei xas de dificuldade para dormir, nervosi smo, sonhos com o trabal ho, dores de cabeça etc.

Palavras-chave SaúdeOcupacional; Comportamento Organizacional; Psicologia Social 


\section{Introdução}

Nos últimos anos, têm ocorrido no Brasil muitas discussões sobre qualidade dos produtos, produtividade e novas estratégias administrativas visando dar maior flexibilidade às empresas e, conseqüentemente, maior produtividade (Freyssenet \& Hirata, 1985; Diesat, 1993).

Em 1990, foi introduzida a liberação das importações, com o objetivo de pressionar as indústrias brasileiras a se tornarem competitivas, dentro das propostas neoliberais do presidente da república então eleito. Foi iniciado o Programa Brasileiro de Competitividade, a fim de "melhorar o desempenho de fabricantes através da criação eapoio a iniciativas no campo da qualidade eprodutividade" (Humphrey, 1992).

Outro acontecimento importante que desencadeou a necessidade de reestruturação da produção foi o Tratado de Maastrich, de 1992, que eliminou as fronteiras entre os países da União Européia, a partir de primeiro de janeiro de 1993, constituindo um grande mercado para exportação e gerando a necessidade de que os produtos sejam feitos segundo regras internacionais de qualidade (Milet et al., 1992).

Nesse contexto de acirramento da competição internacional e em face da necessi dade de melhoria da qualidade dos produtos, passa a ser indispensável o envolvimento do trabalhador com o trabalho (Almeida, 1994), sendo, então, adotadas novas estratégias administrativas que lançam mão da participação no trabal ho, em diversos graus e com diferentes enfoques.

Percebeu-se, portanto, a necessidade de estudar as possíveis relações entre as estratégias administrativas recentemente adotadas e suas repercussões sobre a saúde dos trabalhadores no Brasil.

\section{Metodologia}

Este trabalho foi desenvolvido em uma empresa metalúrgica de São Paulo que vem desenvolvendo um profundo processo de reestruturação produtiva há vários anos e que permaneceu em evidência durante muito tempo, em razão das inovações implantadas e do sucesso financeiro alcançado.

A pesquisa teve por objetivo principal relacionar a saúde dos trabalhadores com as características da administração participativa praticada na empresa em estudo, abordando inclusive a percepção dos trabal hadores sobre seu cotidiano de trabalho e de vida.

A metodologia utilizada foi a qualitativa (Minayo, 1992), empregando-se também ins- trumentos de abordagem quantitativos, tendo sido desenvolvida na forma de um estudo de caso (Ludke \& André, 1986; Triviños, 1992; Becker, 1993).

Realizaram-se entrevistas com todos os trabalhadores da área de produção e também coIheram-se dados relativos à forma de administração praticada na empresa, por meio de entrevistas com pessoas de vários níveis hierárquicos e de levantamento bibliográfico em material publicado pela imprensa escrita no período de 1988 a 1994.

\section{Análise e discussão dos dados}

A empresa é uma metalúrgica de capital nacional e fabrica vários produtos; passou por mudanças estruturais para profissionalizar-se, tendo havido desde o início a opção por um processo participativo envolvendo todos os níveis.

Terceirizou parte das atividades de produção, concentrando suas atividades em al guns produtos e ampliando o seu leque de atuação para a área de serviços e de importações.

No final de 1993, quando da coleta dos dados, a empresa contava com 148 pessoas trabaIhando, e 44 destes atuavam na área de produção.

Como parte da reestruturação, a empresa reuniu suas três unidades num mesmo local e o organograma foi reduzido para quatro níveis hierárquicos: presidente e vice-presidente; gerentes de unidades; coordenadores das áreas de produção de cada unidade e pessoas sem cargos de chefia.

A política salarial baseia-se em quatro níveis: salário de admissão, salário de efetivação (na média do mercado) e dois aumentos de mérito. Todos os trabalhadores são mensalistas e não há pagamento por produção. A empresa oferece vários benefícios e a jornada semanal é de quarenta horas, num único turno de trabaIho. Havendo necessidade, amplia-se a duração da jornada de trabalho diária.

O horário de trabalho é móvel, podendo-se, na área de produção, entrar uma hora mais cedo ou mais tarde, compensando-se no mesmo dia. A participação nos lucros é feita com base no resultado do balanço semestral: se este é positivo, ocorre uma participação proporcional à do resultado obtido. A destinação é decidida em assembléia e a quantia total corresponde a $15 \%$ do lucro bruto ou $22,6 \%$ do lucro líquido. Os resultados para a empresa em virtude das modificações introduzidas na forma de administração foram percebidos no fatura- 
mento por pessoa, que, antes das modificações, era de U\$10.000/ pessoa/ ano e, em junho de 1991, era de U $\$ 60.000$, bem como na rotatividade espontânea, que em alguns momentos aproximou-se de zero.

Heloani (1994), analisando a crise do fordismo nos anos 70, exemplifica a resistência dos trabalhadores à forma de organização do trabal ho rígida citando Durand: “Na indústria automobilística o absenteísmo atingiu na Sué cia 30\% na Volvo antes da crise econômica (com a crise atingiu $20 \%$ ), contra somente $8 \%$ na unidade de Kalmar, ondeaslinhas demontagem tinham sido substituídas por equipes autônomas".

Este exemplo evidencia a relação entre a forma de organização da produção e o absenteísmo, o que certamente pode ser utilizado também para explicar a grande diminuição da rotatividade na empresa em estudo depois das mudanças realizadas na forma de gestão e de organização do trabalho.

As princi pais características da administração praticada na empresa em estudo são a flexibilização da produção e o envolvimento das pessoas através da participação, princípios estes oriundos do Japão. Para Hirata (1993), a produção flexível é um princípio identificável no novo paradigma de produção industrial, exemplificado no modelo japonês; entre as características deste estão as inovações organizacionais e o fim de um "determi nado ti po de relacionamento autoritário na empresa".

Quanto aos efeitos do modelo japonês sobre as pessoas, Dejours (1993) ressalta que “pode-se temer que a transparência se desvie impercepti vel mente de seu curso, em direção à vigi lância general izada e à desapropriação, em nome da razão cívica ou da razão da empresa. Desse modo, o que no início do próprio exercício da inteligência ardilosa é movido pela busca da identidade correria o risco de se desencaminhar no sentido de uma autonomia reduzida e de um control e hi erarquizado o que si gnificaria uma reabertura trágica em direção à alienação...".

A flexibilização da produção incluiu a terceirização de atividades, que possibilita a diminuição dos custos fixos para a empresa, mas pode trazer efeitos deletérios sobre o nível de emprego e as condições de trabalho para os terceirizados.

Em pesquisa realizada pelo Dieese (1993), foram detectados os seguintes efeitos da terceirização: diminuição dos benefícios sociais, salários mais baixos, ausência de equipamentos de proteção, trabalho sem registro em carteira, perda da representação sindical em razão da transferência de cada esfera da produção para uma área e, conseqüentemente, para uma outra representação, entre outros.

Para o Dieese/ Diesat (1994) "a terceirização tem sido mais uma estratégia de redução de custos pela expl oração das relações precárias de trabal ho do que de uma redução de custos resultante do aumento de produtividade"; ressaltam ainda que "manti do o padrão atual aprofunda o processo de exclusão social brasileiro".

Um exemplo é dado por Gorz (1988) apud Mattoso (1992): “Nos próximos dez anos, segundo pesquisa da Central Sindical Alemã (DGB) do total detrabal hadores ocupados e desempre gados, $25 \%$ serão trabal hadores periféricos nas empresas de subcontratação e serviços; 50\% estarão desempregados ou real izando trabalhos ocasionais. Apenas 25\% serão trabalhadores qual ificados de grandes empresas e protegi dos pelas convenções coleti vas".

A empresa em estudo tem alguns princípios relativos à participação e à liberdade; vale destacar o by pass que possibilita que as pessoas possam buscar a informação de que precisam para efetuar seu trabalho com quem for necessário; isso agiliza o trabalho para a empresa e é percebido pelas pessoas entrevistadas como algo muito positivo, como será visto mais adiante.

Considerou-se positivo também o fato de não existirem na empresa práticas de premiação individual ou de concorrência entre grupos de trabalho, que poderiam levar ao sofrimento pela exploração da rivalidade inerente ao processo de competição. O fato de não haver atividades de lazer coletivas no tempo livre ligadas à empresa pode ser igualmente considerado positivo. Não há pagamento por produção, o que poderia prevenir um ritmo de trabalho intenso devido à busca de maiores ganhos financeiros.

Há ainda a possibilidade de assumir os erros cometidos no trabalho, o que pode ter efeitos benéficos sobre a saúde das pessoas, já que não há necessidade de ocultar as fal has cometidas e nem de lidar com o medo e a culpa decorrentes desta situação.

Entre as características relacionadas à organização do trabalho, está a adoção da polivalência; esta será discutida mais à frente, mas vale destacar agora que a vivência desta é sempre ambígua, uma vez que amplia o conhecimento e a experiência profissional dos envolvidos, ao mesmo tempo intensificando, porém, o ritmo de trabalho e gerando insatisfação no momento da avaliação de desempenho, conforme relatado pelos entrevistados.

A população de estudo constituiu-se de quarenta pessoas, todas do sexo masculino, e 
metade delas tem de trinta a quarenta anos. Quanto ao grau de escolaridade, 55\% têm até quatro anos; $7,5 \%$ têm oito e $12,5 \%$ têm onze (segundo grau completo).

O tempo de trabalho na empresa é grande para a maioria dos entrevistados: $40 \%$ destes têm de seis a dez anos incompletos; $20 \%$, de dez a 14 anos incompletos e 17,5\% têm mais de 14 anos de atividade neste emprego. Vale lembrar que é princípio da empresa que indivíduos trabal hando para ela há mais de três anos tenham sua demissão aprovada por um grande número de pessoas.

O número de funções que cada trabalhador executa é variado: $17,5 \%$ exercem uma; $25 \%$, duas; $35 \%$, três; $15 \%$, quatro e $7,5 \%$, cinco.

Com relação à percepção sobre a intensidade do ritmo de trabal ho, $10 \%$ consideram o ritmo muito intenso, $27,5 \%$, intenso, e $62,5 \%$, regular. Vários entrevistados ressaltaram a intensificação do ritmo de trabalho na última semana do mês, em virtude de as encomendas de produtos se concentrarem neste período. É uma das conseqüências da flexibilização da produção, que implica a não-manutenção de estoques.

Entre os que referem ritmo de trabal ho muito intenso, al guns relacionam este fato com o comprometimento da qualidade do sono e da vida familiar, entre outros. Uma pessoa lembrou a intensificação do ritmo de trabalho como algo positivo diante da atual situação sócio-econômica e a possibilidade de vir a ficar desempregado.

Com respeito ao controle sobre o trabalho, $85 \%$ referem tê-lo sempre e $15 \%$, às vezes. A percepção de que tem controle sobre o próprio trabal ho é lembrada juntamente com a liberdade exemplificada na fala de um trabalhador: “...entre os próprios colegas da seção a gente combina, um vai fazer isso, o outro aquilo, aquela tendência, às vezes até sem o dirigente saber, conversa cada um (...) localiza aquele local para fazer aquele dia e nós sabemos de manhã ejá sabemos o que fazer. Às vezes o di rigente chega (...) mas el e não opina nada, o importante é que sai a o serviço, dividem entre os colegas".

Quanto ao conhecimento para realização do próprio trabalho, $82,5 \%$ referem tê-lo sempre e $17,5 \%$, quase sempre. Já o conhecimento para realizar a tarefa de outra pessoa, $60 \%$ relatam tê-lo sempre; $27,5 \%$, quase sempre, e $12,5 \%$, às vezes.

Vale ressaltar que executar freqüentemente uma tarefa que não se domina pode ser fonte de ansiedade e de sofrimento. Também deve ser lembrado que fazer tarefas mais simples que a qualificação de que se dispõe pode gerar sofrimento, com repercussões negativas sobre a saúde.

Quando questionados se apreciam cobrir o trabalho de outra pessoa, 90\% referem gostar. A justificativa para o sim vem da possibilidade de aprendizado, de ampliação da experiência profissional e de sentir que é uma obrigação.

Também o aumento da carga de trabal ho é lembrado “...automaticamente vocêestá aprendendo, você não está só fazendo aquilo, você muda, tem a oportunidade de fazer algo diferente (...) ao mesmo tempo, ao fazer tudo isso você se torna, acaba se carregando demais, tem uma sobrecarga, por exemplo, não seria pra gente (citou uma atividade), mas você está cobrindo a falta do (citou o profissional encarregado da atividade), então vocêfaz, você está se carregando mais com outra operação".

Ainda em relação à polivalência, foi citada por um trabalhador a impossibilidade de escoIha, pois é necessário cooperar para manter o emprego.

Silva (1991), analisa dois casos de negociação sobre o conteúdo das ocupações. Citando Leite, relata um ocorrido no Brasil, no qual os trabal hadores negociaram para que o conteúdo das ocupações se ampliasse; o outro foi encontrado por ela na Grã-Bretanha, onde a gerência tentou impor uma ampliação do conteúdo das ocupações e enfrentou uma recusa dos trabalhadores. A autora conclui que "as possibilidades para a implementação deformas detrabal ho mais flexíveis são mais abrangentes no Brasil".

Outro ponto é que as pessoas com maior qualificação têm de fazer também tarefas mais simples, o que foi referido por vários entrevistados como um fator de desânimo e de ausência de perspectivas; além disso, são poucos os trabal hadores com maior conhecimento específico, e muitas vezes em uma unidade de produção apenas uma pessoa domina determinada tarefa, o que implica sobrecarga.

$\mathrm{Na}$ fala dos entrevistados que vivem esta situação, a polivalência aparece como prejudicial à saúde sob vários aspectos, como o aumento da carga de trabalho, a vivência da responsabilidade de ter de fazer o trabal ho sozinho, a autodesvalorização por ter de cobrir tarefas menos complexas e a falta de perspectivas advinda desta situação.

Quanto ao uso da criatividade no trabalho, $62,5 \%$ referem utilizá-la sempre; 7,5\%, quase sempre, e $30 \%$, às vezes. A forma como o trabaIho permite o uso da criatividade e seus efeitos sobre a produtividade pode ser exemplificado pela resposta de um trabalhador: “...eu gosto 
mais decriar as coisas em cima do que eu estou fazendo eeles me dão chance para fazer isto, às vezes eu tento mudar alguma coisa eàs vezes fica melhor o custo e também melhor para a mão-de-obra, el es me dão chance de fazer isto...".

Em relação à liberdade vivenciada no trabalho, $97,5 \%$ referem tê-la. Nesse sentido, os entrevistados levantaram alguns pontos, como a ausência de controle direto. Também fizeram referência ao controle estrito por que passaram em empregos anteriores e ao controle feito sobre os trabalhadores dentro da própria empresa $X$, no período anterior às modificações descritas neste estudo. Entre os entrevistados, um trabal hador referiu perseguição por parte da chefia no momento atual.

Para discussão desses aspectos vale destacar o modelo de trabalho brasileiro (Coriat, 1994:12), que é centrado na flexibilidade externa, no trabalho pouco ou não qualificado, subremunerado, tendo como recurso sistemático uma mão-de-obra instável e precária. Este é um ponto crucial, que pode ajudar na compreensão da questão da cooperação dos trabaIhadores em face das novas formas de organização do processo de produção e de gerenciamento no Brasil.

Na discussão sobre a liberdade no trabalho, outro aspecto lembrado é a possibilidade de se buscarem as informações de que se precisa para o trabalho onde for necessário, sem ter de seguir os níveis hierárquicos, o by pass: “... ehoje continuo com a mesma carga de trabal ho, mas ainda tenho poder de decisão em alguns casos e tenho um pouco deliberdade, mas porque tem al gumas pessoas que partici pam, pela situação da empresa, a gente pode procurar mais pessoas..."; “...o si stema da firma eu gostei eacabei ficando, já estou há nove anos (...) por causa (...) acho que o quemesegurou aqui foi a democracia (...) hoje vocêtem uma total li berdade de sair daqui da montagem, ir lá conversar com o engenheiro, o vendedor, o diretor, o supervisor, do mesmo jei to que eu converso com um ajudante lá na fábrica...".

Nas falas supracitadas e em várias outras, a possibilidade de buscar as informações com quem for necessário independente do nível hierárquico é sempre referida como muito positiva pelos entrevistados, sugerindo que o by pass atua como uma forma de reconhecimento do saber dos trabalhadores pela empresa, com efeitos positivos para a auto-estima, a identidade e, conseqüentemente, a saúde. Certamente há também ganhos para a empresa, que consegue melhoria da qualidade dos produtos e redução dos custos. Foi igualmente conside- rada positiva a possibilidade de decidir sobre as pausas no trabalho.

A possibilidade de assumir os erros também é lembrada, associada com a liberdade : "...a gente muda, né, se a gente tem liberdade tem agora condi ções de produzir mais e se sentir mais mel hor; você sabe que pressionado você faz, mas não faz contente, dessa forma vocêtrabal ha mel hor, vocêtem atéliberdade de vocêerrar e poder chegar efalar: - Errei. Se fosse outro lugar, não, vocêia pensar: - O que eu vou fazer agora? E setiver um jeito dele esconder aquele erro ele esconde, assi m vai ...".

Em seminário realizado em São Paulo, em abril de 1994, o Professor Dejours, quando indagado se os sistemas de administração participativos poderiam levar a uma aproximação entre a organização do trabal ho real e a prescrita, respondeu, partindo da experiência francesa, que isso seria possível se houvesse a explicitação do 'quebra-galho', passando pelo coletivo de trabal hadores, incluindo os colegas e a chefia.

As falas de al guns entrevistados sobre o uso da criatividade no trabalho, possibilidade de by pass e de assumir o erro, são sugestivas de uma aproximação entre organização do trabalho real e prescrita.

O contraponto é feito por um trabalhador, que ressalta a vigilância dos colegas: “....a vigilância queeu sinto agora é uma base entreamizade, porque se você está trabalhando em conjunto não adianta, se tem três pessoas trabaIhando e uma encostar os outros dois vão cuidar dele: - Ó, só eu que faço, vocênão faz. Quer dizer, não precisa mais ninguém, dos três ali, se um acha que 'ah, hoje eu não quero nada', alguém vai pegar no pé dele. Agora se tem uma justificativa, se você percebe que a pessoa realmente não tá legal, que não é todo dia que a pessoa está com a mesma disposição, aí tudo bem...".

Em relação a sentir que o trabalho é reconhecido pela empresa, $75 \%$ referem que sim e $22,5 \%$ que não. O conhecimento dos critérios de avaliação de desempenho utilizados pela empresa é referido por apenas 55\% dos entrevistados, o que pode representar uma fonte de tensão e ansi edade, com conseqüências negativas sobre a saúde. Conforme Seligmann-Silva (1995) “...quando existe um chefe ou supervisor visível com o qual é possível falar e mesmo discutir, a si tuação émenos intranqüilizadora do que quando a vigilância se oculta, atuando através de mecanismos de controle desconhecidos para o empregado. Por exemplo, quando ele não é informado sobre os critérios utilizados para avaliar seu desempenho ou decidir sua de- 
missão". Alguns entrevistados ressaltaram a insatisfação em relação ao salário e aos critérios de avaliação de desempenho em face da polivalência.

Com relação aos efeitos do trabalho sobre a vida familiar, Seligmann-Silva (1990b)destaca a complexidade dessa interação onde “as vivências do mundo doméstico irão ecoar no ambientelaboral, da mesma forma que os fenômenos que o trabal ho imprime no conjunto psicofísico do trabal hador irão se fazer sentir na qualidade de seu convívio e de suas práti cas nas horas em que permanece em casa".

Sobre ter havido modificações na vida pessoal decorrentes do tipo de administração praticada na empresa, $60 \%$ referem que sim. Entre os que notaram mudanças na vida pessoal, várias pessoas citaram a liberdade no trabalho como um fator de melhoria no relacionamento com os colegas de trabalho e com a família: “Acho que modifica porque vocêjá pensou você trabalhar, o encarregado no teu pé; chega a tarde, você está uma pilha de nervos, às vezes pode até descontar em casa...".

Um trabalhador referiu mudanças de forma negativa na vida pessoal por causa da intensificação do ritmo de trabalho: “...sevocê hoje vem a trabalhar um pouco mais não posso dizer pra você que a empresa seja culpada, tem um padrão, vocêtem ritmo de serviço, então você vem naquel e ritmo de serviço, então você vem naquele ritmo. Agora, muitas vezes, por vocênão terminar uma tarefa de serviço, você tem que acelerar um pouco maise isso aí pode fazer com que você venha a modificar com a família...".

Na comparação com experiências de trabaIho anteriores, os efeitos da liberdade, ou da falta dela, também foram lembrados: “... um probleminha, eu chegava em casa, falava alguma coisa para mim eeu já estourava, minha cabeça estava na empresa, então isso aí mudou". "A coisa mais tristeé vocêtrabal har numa empresa em que vocêé pressionado, o cara fala assim: ol ha vocêconversou com seu colega aí do lado e não pode fazer isso...; você chegou um minuto atrasado, vai ser descontado o domingo, o sábado e não sei mais o quê e começa a pressi onar você pensando que você não entende das coisas..., vai fazer pressão sobre você, você vai pra casa chateado eacaba prejudicando a família...".

Outro aspecto importante que surgiu no relato de um trabalhador foi a referência à possibilidade de ausentar-se eventualmente do trabalho no caso de ter problemas para resolver em casa: ...às vezes, a família, a gente tá aqui, surge um problema em casa, a gente sai ou às vezes não vem trabalhar, depois chega aqui, a gente conversa com os encarregados, el es compreendem, nos outros lugares em que eu tenho trabalhado isso foi rígido, e aqui não. Então mudou bastante o sistema da família, atéa própria família também nota, se eu tenho mais problema em casa, a firma reconhece, atéapóia a gente; e em outras em que eu tenho trabal hado, não, ela quer o serviço, ela quer só o serviço, agora os empregados, os problemas... então neste ponto eu acho bastante interessanteaqui...".

A possibilidade de reconhecimento e compreensão dos eventuais problemas familiares pela empresa emerge no relato do trabalhador como algo muito positivo. Em trabalho realizado de 1981 a 1983 com trabalhadores industriais de Cubatão e operários de empresa siderúrgica de São Paulo, Seligmann-Silva (1990b) estudou os efeitos do trabalho em turnos alternados sobre o cotidiano familiar e relata a sobrecarga referida pelas esposas dos trabal hadores, por terem que assumir as responsabilidades familiares sozinhas. Neste contexto, a situação anteriormente relatada pelo entrevistado, de ter flexibilidade no trabalho para ausentar-se e participar das resoluções dos problemas familiares, pode trazer repercussões positivas para a convivência familiar.

Outro ponto já comentado, mas que vale a pena ser resgatado na discussão sobre a vida familiar, é que, quanto à polivalência, um aspecto positivo referido pelos entrevistados era o de cobrir o trabal ho de outros colegas porque talvez houvesse disponibilidade do outro em fazer o mesmo num caso de necessidade.

Em relação às atividades desenvolvidas no tempo livre, Seligmann-Silva (1990a:277) ressalta que "o lazer é consi derado defesa contra o esvaziamento existencial eo cortejo demanifestações de sofrimento mental associadas ao trabal ho e como componente importante na consecução de mel hores padrões de qualidade de vida".

A mesma autora cita as características necessárias para que o lazer possa propiciar os objetivos acima descritos: atividades que possibilitem prazer, descontração, desligamento das preocupações do trabalho cotidiano, enriquecimento existencial, e que sejam emocionalmente significativas e socialmente gratificantes. Entre as atividades desenvolvidas no tempo livre referidas pelos entrevistados, a mais freqüente foi ver televisão (85\%), que exige uma atitude passiva por parte das pessoas. Foram citadas também formas de entretenimento que têm um caráter ativo, de integração e de convívio social: visitar amigos (67,5\%), visitar parentes $(62,5 \%)$, participar de atividade religiosa (47,5\%), participar de reunião do sin- 
dicato (35\%), praticar esportes (27,5\%) e beber cerveja no bar, jogar sinuca, assistir a jogo de futebol no campo (8,8\% cada atividade).

A referência à realização de serviços em casa foi feita por $32,5 \%$ dos entrevistados. Os problemas de saúde referidos foram vários e, entre estes, 53,8\% foram relacionados ao trabalho. Os problemas de saúde no momento atual relatados como relacionados ao trabalho são: perda auditiva, cansaço na vista, hérnia inguinal, desvio de coluna, gripe, varizes e sinusite, todos compatíveis com a história de trabalho e de vida relatada pelos entrevistados.

As queixas de saúde que foram referidas como freqüentes nos últimos dois anos são: dores de cabeça e nas costas (40\%), dificuldade para dormir (17,5\%), pressão alta (12,5\%), cansaço que não passa com descanso (10\%), entre outros. Chama a atenção o fato de que as queixas referidas são sugestivas de terem origem psicossomática, como resultado de exigências do trabalho, mas, quando indagados sobre o ritmo de trabalho, a maior parte das pessoas classifica-o como regular, ressaltada a intensificação na última semana do mês.

Um dos entrevistados explicitou a contaminação de sua vida fora do trabalho em decorrência do ritmo excessivo de trabalho “... A gente sempre tem uma programação equando você vai sair para trabalhar vocêfica assim pensando naquilo que vocêvai fazer primeiro, se está tudo em ordem, como você vai fazer para colocar aquilo em prática, para adiantar o serviço (...) eu, em casa, até sonhar com o trabalho eu sonho...".

Os efeitos mais perversos da adoção de novas formas de organização do trabalho e de gestão vão recair não sobre os trabalhadores da empresa em estudo, mas sobre os que foram excluídos do mercado de trabalho quando das modificações ocorridas, o que é percebido pelos que permaneceram trabalhando: ... Olha, a gente sempretinha esperança deque no ano que vem mel hora, o ano que vem mel hora; quando iniciou todo esse processo com dispensa, vamos trabal har com terceiro, aí, ah, isso écoisa de um ano, melhora; só que agora a gente não tem mais essa esperança, essa expectativa que no ano que vem melhora. Nesse sentido eu não tenho mais esperança eu não sei como pensar como meus filhos vão, eu tenho um filho de $X$ anos, que está estudando, graças a Deus ele é muito esforçado, o que el e vai enfrentar pela frente eu não sei...".

Nesta perspectiva, Mattoso (1994) analisa as modificações no mundo do trabalho nos países avançados e relata a ocorrência de dois desdobramentos; o primeiro aponta para o sur- gimento da "figura de um novo trabalhador, mais escol arizado, parti ci pativo e polival ente (em contraposi ção aos trabal hadores especializados, parcel izados, desqualifi cados da produção fordista) e até mesmo portadores de uma revalorização da ética e da utopia do trabalho"; isto se dá com os trabalhadores das empresas líderes. O segundo desdobramento consiste na contrapartida do primeiro "à crescente massa de trabalhadores que perdem seus antigos direitose, não se inserindo de forma competitiva no novo paradigma tecnológico, tornam-se desempregados, marginalizados, ou trabalham sob novas formas de trabal ho e de qual ificação, em relações muitas vezes precárias...".

O mesmo autor destaca o contexto em que emergem estas mudanças no mundo do trabaIho nos países avançados, "em condições de debilidade defensiva do trabalho organizado e de fortalecimento ofensivo do capital estruturado. Em nome da competitividade internacional, o capital busca reestruturar-se movendo-se contra o trabalho organizado".

\section{Conclusão}

No que diz respeito às características da participação praticada na empresa em estudo, concluiu-se que ela é abrangente, permeando as atividades lá desenvolvidas, e para a maior parte dos entrevistados tem um significado de liberdade, respeito e satisfação em relação ao trabalho; em vários momentos houve comparação com empregos anteriores, de onde vem a experiência de ter sofrido vigilância estrita das atividades no trabalho.

A reestruturação produtiva empreendida na empresa baseou-se na flexibilização da produção, mediante a terceirização de atividades e o uso da polivalência na organização do trabalho, paralelamente ao desenvolvimento de um processo participativo.

As características dessa forma de administração correspondem ao novo paradigma industrial e de seu expoente maior, o Japão, lembrando que são as formas de organização do trabalho que seguem as idéias oriundas desse país, e não as relações de trabalho.

A participação se dá através de mecanismos que incluem o reduzido número de níveis hierárquicos, a ausência de vigilância estrita, o trabalho em grupo, o horário de trabal ho móvel, a escolha dos momentos para pausa no trabalho, os canais de comunicação, diretos (by pass) e indiretos (a comissão de fábrica) e a participação nos resultados, por meio da participação nos lucros. 
A polivalência é uma questão complexa, que foi citada pelos entrevistados às vezes de forma muito positiva e/ ou muito negativa. Entre os aspectos positivos citaram-se a ampliação do aprendizado, a possibilidade de os colegas fazerem o trabalho no caso do trabalhador ter um problema; entre os aspectos negativos, foram lembradas a intensificação do trabalho, a sobrecarga de trabal ho e de responsabilidade dos que desempenham sozinhos uma função, em razão da qualificação específica.

Alguns se sentem injustiçados em relação ao salário e ao reconhecimento do trabalho pela empresa, uma vez que desempenham várias tarefas.

Com relação à percepção e ao significado atribuído ao trabalho, al gumas pessoas destacam muito positivamente a vivência neste, ressaltando a liberdade e o respeito que sentem, atribuindo a estes uma melhora na vida fora do trabalho. Em vários momentos das entrevistas os trabalhadores citam o bom relacionamento com os colegas, com as chefias, a solidariedade

\section{Referências}

ALMEIDA, J. M., 1994. Produtividade e Participação: Um Estudo de Caso. Rio de Janeiro: Ed. Qualitymark.

BECKER, H. S., 1993. Métodos de Pesquisa em Ciências Sociais. São Paulo: Ed. Hucitec.

CORIAT, B., 1994. Pensar pelo Avesso: O Model o Japonês de Trabal ho e Organização. Rio de Janeiro: Ed. Revan e Editora da UFRJ.

DEJOURS, C., 1993. Inteligência operária e organização do trabalho: a propósito do modelo japonês de produção. In: Sobreo Modelo Japonês (H. Hirata, org.), pp. 281-309. São Paulo: Edusp.

DIEESE (Departamento Intersindical de Estatística e Estudos Sócio-Econômicos), 1993. Os trabalhadores frente à terceirização. Pesquisa Dieese, 07: 2-3.

DIEESE/DIESAT (Departamento Intersindical de Estatística e Estudos Sócio-Econômicos/ Departamento Intersindical de Estudos e Pesquisa sobre a Saúde e o Trabalho), 1994. Saúde do trabalhador e reestruturação produtiva. In: II Conferência Estadual deSaúdedo Trabalhador. São Paulo: DIEESE. e a confiança que vivenciam na empresa. Em alguns momentos, pode ser percebida na fala dos entrevistados a introjeção dos valores da empresa e a exacerbação do autocontrole, decorrentes da forma de organização do trabaIho.

Para uma parte dos entrevistados não houve referências especiais ao trabalho realizado na empresa.

Para outros, as características da organização do trabalho praticada na empresa geram efeitos deletérios sobre as pessoas por causa da intensificação do ritmo de trabalho, afetando a vida familiar e interferindo na saúde, gerando queixas de dificuldade para dormir, nervosismo, sonhos com o trabalho, dores de cabeça etc.

Apesar da classificação acima adotada, vale ressaltar que, para muitos, a vivência é contraditória; em alguns momentos da entrevista a forma de administração aparece muito positivamente e em outros momentos, de forma oposta.
DIESAT (Departamento Intersindical de Estudos e Pesquisa sobre a Saúde e o Trabalho), 1993. Qualidade, produtividade, saúde e segurança do trabalhador. Resenha, 08:2-8.

FREYSSENET, M. \& HIRATA, H., 1985. Mudanças tecnológicas e participação dos trabalhadores: os círculos de controle de qualidade no Japão. Revista deAdministração de Empresa, 25:5-21.

HELOANI, R., 1994. Organização do Trabalho e Administração: Uma Visão Multidisciplinar. São Paulo: Ed. Cortez.

HIRATA, H., (org.), 1993. Sobreo Modelo Japonês. São Paulo: Edusp.

HUMPRHEY, J., 1992. The management of labour and the move towards leaner production systems in the third world: the case of Brazil. In: International Institute for Labour Studies Forum: "The Challenge of Lean Production: How are Firms and Unions Responding?". Geneva (mimeo.).

LUDKE, M. \& ANDRÉ, M. E. D. A., 1986. Pesquisa em Educação: Abordagens Qualitativas. São Paulo: Ed. Pedagógica Universitária. 
MATTOSO, J. E. L., 1992. Notas sobre a terceira revolução industrial, crise e trabalho no Brasil. In: Gestão da Qualidade: Tecnologia e Participação (R. M. S. de M. Soares, org.), pp. 170-190. Brasília: Codeplan.

MATTOSO, J. E., 1994. O novo e inseguro mundo do trabalho nos países avançados. In: O Mundo do Trabalho (C. A. Oliveira, J. E. L. Mattoso, J. F. Siqueira Neto, M. Pochmann, M. \& A. Oliveira, orgs.), pp. 521-562. São Paulo: Ed. Página Aberta.

MILET, E. B.; AZAMBUJA, T. T. \&VARELLA FILHO, A. C., 1992. ISO Série 9000. Rio de Janeiro: MCG.

MINAYO, M. C. S., 1992. O Desafio do Conhecimento: Pesquisa Qualitativa em Saúde. São Paulo: Hucitec/Rio de Janeiro: Abrasco.

SELIGM ANN-SI LVA, E., 1995. Psicopatologia e psicodinâmica do trabalho. In: Patologia do TrabaIho (R. Mendes, org.), pp. 287-310. São Paulo: Atheneu.
SELIGM ANN-SILVA, E., 1990a. Saúde mental e trabaIho. In: Cidadania e Loucura: Políticas de Saúde Mental no Brasil (S. A. Tundis \& N. R. Costa, orgs.), pp. 217-288. Petrópolis: Ed. Vozes/ AbrasCo.

SELI GM ANN-SI LVA, E., 1990b. Sociabilidade, trabaIho e loucura: repercussões das condições de trabalho sobre a vida familiar. Jornal Brasileiro de Psiquiatria, 39 (Supl. 2):235-275.

SILVA, E. B., 1991. Refazendo a Fábrica Fordista. São Paulo: Ed. Hucitec/ Fapesp.

TRIVIÑUS, A. N. S., 1992. Introdução à Pesquisa em Ciências Sociais: A Pesquisa Qualitativa em Educação. São Paulo: Ed. Atlas. 